\title{
The Malnutrition of Obesity: Micronutrient Deficiencies That Promote Diabetes
}

\author{
Michael Via \\ Division of Endocrinology and Metabolism, Beth Israel Medical Center, Albert Einstein College of Medicine, \\ 55 East 34th St, USA \\ Correspondence should be addressed to Michael Via, mvia@chpnet.org
}

Received 13 December 2011; Accepted 5 January 2012

Academic Editors: C. Anderwald and A. Hishinuma

Copyright ( 2012 Michael Via. This is an open access article distributed under the Creative Commons Attribution License, which permits unrestricted use, distribution, and reproduction in any medium, provided the original work is properly cited.

Obesity and diabetes are increasing in prevalence worldwide. Despite excessive dietary consumption, obese individuals have high rates of micronutrient deficiencies. Deficiencies of specific vitamins and minerals that play important roles in glucose metabolism and insulin signaling pathways may contribute to the development of diabetes in the obese population. This paper reviews the current evidence supporting this hypothesis.

\section{Introduction}

Obesity is highly prevalent both in the United States and worldwide and is projected to surpass tobacco use as the most economically important modifiable risk factor in public health and disease [1-3]. Multiple genetic, environmental and behavioral factors contribute to the increasing trend in obesity $[1,3]$. The increased availability of low-cost, highcalorie, nutrient-poor foods over the past four decades is a key component to the rise in obesity worldwide [3]. Modern agriculture and food processing techniques lead to a relative reduction in the micronutrient content of common foods [4]. Despite an excess of dietary calorie intake, obese individuals have relatively high rates of micronutrient deficiencies $[5,6]$.

The importance of certain micronutrients as cofactors in glucose metabolic pathways, pancreatic $\beta$-cell function and in the insulin signaling cascade suggests that deficiency in these micronutrients may play a role in the development of type 2 diabetes.

The risk of type 2 diabetes is increased 4 -fold in obese patients [7]. The causal relationship of obesity and diabetes is complex. Increased insulin resistance, incretin hormone resistance, oxidative stress, pancreatic $\beta$-cell dysfunction, and genetic and behavioral factors all contribute to the development of diabetes in obese individuals [8]. Specific micronutrient deficiencies in obese individuals may also influence the development of type 2 diabetes.

\section{Vitamin D}

High rates of vitamin D insufficiency and frank deficiency have been reported in obese individuals and in diabetics. The prevalence of vitamin D insufficiency (defined as $<30 \mathrm{mg} / \mathrm{dL}$ ) in obese individuals ranges from $80-90 \%[5,9]$. While some controversy exists over treatment targets in individuals with mild insufficiency of vitamin D especially for the purported extraskeletal effects of vitamin D supplementation, $[10,11]$ a significant amount of evidence suggests there may be some beneficial effect in using vitamin D supplementation for improvement in glucose metabolism and insulin signaling in patients with type 2 diabetes or impaired glucose tolerance [12].

Preclinical evidence for the role of vitamin D in insulin secretion and function includes the presence of vitamin $\mathrm{D}$ receptors in human pancreatic $\beta$-cells, the detection of 1- $\alpha$ hydroxylase activity, and insulin gene transcription responsiveness to vitamin $D$ in pancreatic $\beta$-cells $[13-16]$. In vitamin $\mathrm{D}$ deficient animals, pancreatic $\beta$-cell dysfunction is noted, which is restored with vitamin D supplementation [17-19]. Many epidemiologic studies demonstrate an inverse relationship between 25-hydroxyvitamin D level and 
prevalence of type 2 diabetes [20-25]. Seasonal fluctuations in glycemic control in type 2 diabetics may also be due in part to fluctuations in vitamin D levels, though behavioral differences may also explain these findings $[26,27]$.

Recent reviews and metaanalyses of clinical trials suggest a potential effect of vitamin $\mathrm{D}$ supplementation on the development of type 2 diabetes in high-risk individuals $[12,16$, 28]. Three of five randomized trials demonstrate improvements in insulin sensitivity with vitamin D supplementation in subjects with insulin resistance or impaired fasting glucose [29-31]. One study showed improved oral glucose tolerance and insulin sensitivity in 71 obese males supplementation with 120,000 i.u. of cholecalciferol or placebo every 2 weeks after 6 weeks of followup [29]. A second trial showed improvement in insulin sensitivity and decreased fasting insulin levels in 81 vitamin D deficient subjects with baseline insulin resistance given 4,000 i.u. cholecalciferol daily or placebo [31]. In the third trial, subjects with impaired fasting glucose showed stability in fasting glucose levels after three years of daily supplementation of 700 i.u. of cholecalciferol compared to an increase in fasting glucose in the placebo group [30]. Two trials failed to show effect of vitamin D supplementation $[32,33]$. One of these used only low doses of vitamin D (400 i.u. daily) that may not have been adequate; over $89 \%$ of participants did not achieve normal levels of vitamin $\mathrm{D}$ by the end of the trial [32]. Based on the results these five studies, patients at risk for development of type 2 diabetes may benefit from vitamin $\mathrm{D}$ supplementation.

The use of vitamin $\mathrm{D}$ in patients already diagnosed with type 2 diabetes has also been investigated. Of four recently published randomized trials, two demonstrate improvements in glycemic control [33-36]. In one trial, 92 early type 2 diabetics (defined by glycosylated hemoglobin $\geq 5.8 \%$ and 2-hour postprandial glucose $\geq 140 \mathrm{mg} / \mathrm{dL}$ ) were randomized to receive 2,000 i.u. of cholecalciferol or placebo daily for 4 weeks [34]. Significant improvements in the measured glucose disposition index were noted in the treatment group. In another trial, 90 type 2 diabetic patients given 1,000 i.u. cholecalciferol or placebo daily for 12 weeks demonstrated decreased glycosylated hemoglobin by $0.4 \%$, decreased fasting glucose by $13 \mathrm{mg} / \mathrm{dL}$, improved insulin sensitivity, and 1$2 \mathrm{~kg}$ weight loss in the treatment group [35].

In one of the trials that demonstrated negligible effect of vitamin D supplementation in type 2 diabetics, patients given single dose of 300,000 i.u. of cholecalciferol found no change in fasting glucose, fructosamine, or insulin sensitivity despite normalization of plasma 25-hydroxyvitamin D levels [33]. However, adequate levels of serum 25-hydroxyvitamin $\mathrm{D}$ were not achieved in this trial. The average 25-hydroxyvitamin D level at the end of followup was $16 \mathrm{ng} / \mathrm{dL}$.

The other negative study was a randomized trial with 6 weeks of followup in which 32 diabetic patients were given 40,000 i.u. of cholecalciferol or placebo every two weeks and showed no difference in glycosylated hemoglobin, fasting, glucose or insulin sensitivity [36]. Subjects in both treatment arms had a relatively high baseline 25-hydroxyvitamin D level in this trial $(24 \mathrm{ng} / \mathrm{dL})$, which may have contributed to the negative results.
The use of vitamin D supplementation specifically for improvements in insulin sensitivity remains a controversial issue. There are presently ten ongoing clinical trials evaluating the use of vitamin D supplementation in type 2 diabetic patients and patients with impaired glucose tolerance, which may provide further guidance on this issue. Given the high rates of vitamin D insufficiency in the obese population and the observed benefits, clinicians may consider vitamin D supplementation in this population.

\section{Chromium}

Chromium was recognized as an essential trace metal required in the insulin signal cascade through animal dietary experiments that were first performed in the 1950s [37, 38]. Molecular and cell culture studies demonstrate that chromium bound to the oligopeptide chromodulin enhances the tyrosine kinase activity of the insulin receptor and inhibits phosphotyrosine phosphatase activity, thereby amplifying the intracellular insulin signal cascade $[39,40]$.

Chromium deficiency in humans has been identified in severely malnourished patients who demonstrate severe insulin resistance, hyperglycemia, hypertriglyceridemia, and painful neuropathy. In published case reports, these symptoms and signs completely and rapidly resolve after the administration of chromium [41-44]. As a result of these findings, the inclusion of chromium in parenteral nutrition formulas has become standard [45].

The main dietary sources of chromium include yeast, meats, and wheat germ. The use of stainless steel pots and utensils increases the chromium content of food as traces of chromium are liberated from the steel during preparation. Body stores of chromium are intracellular, mainly in the liver. Individuals with type 2 diabetes have $20-40 \%$ lower blood chromium levels and 40-50\% lower chromium levels measured in scalp hair compared to healthy controls [46-49]. Chromium deficiency rates in obese individuals are currently not available.

A number of clinical trials have investigated the role of oral chromium supplementation in patients with type 2 diabetes, insulin resistance, and the metabolic syndrome [50, 51]. In general, the results of these trials show only modest improvements in markers of insulin resistance and glucose metabolism. The greatest effects are noted in trials that administer higher doses and supplement with compounds such as chromium picolinate that provide a higher bioavailability of chromium. A review of 15 trials using chromium picolinate notes consistent improvements in glycemic control in 13 of the 15 trials, with an overall average decrease in glycosylated hemoglobin of $0.95 \%$ [52].

As with many supplements, the use of chromium supplementation in diabetic patients or in patients at risk for diabetes is controversial. The results of clinical trials that administer high doses of high bioavailability chromium suggest that supplementation with chromium may improve insulin resistance and glycemic control in diabetes [52]. Recently, the United States Food and Drug Administration release a Quality Health Claim regarding the use and safety of chromium picolinate for the treatment of insulin resistance 
[53]. This therapy may be beneficial in obese patients at risk for diabetes.

\section{Biotin}

Biotin is a water soluble vitamin that serves as a cofactor for carboxylase enzymes in fatty acid synthetic pathways, the citric acid cycle, and aminoacid metabolism [54]. In addition to its biochemical function, circulating biotin regulates gene expression [55]. Prevalence data regarding rates of biotin deficiency in obese individuals or in diabetic patients are not presently available. However, patients with type 2 diabetes demonstrate lower circulating levels of biotin compared to healthy controls and an inverse relationship between biotin level and fasting plasma glucose has been reported [56, 57].

Animal studies demonstrate the development of insulin resistance in biotin deficient rats that resolves with biotin replacement [62]. At least part of the underlying mechanism of this phenomenon involves biotin-induced hexokinase gene expression that increases hepatic glucose uptake [63, 64]. Biotin also regulates transcription of the insulin receptor and improves pancreatic $\beta$-cell function $[65,66]$.

To date, only a few human trials evaluating the efficacy of biotin supplementation on glycemic control have been conducted. In one longitudinal study, diabetic patients treated for 28 days with $15 \mathrm{mg}$ biotin supplements had improvements in fasting glucose and insulin levels [54, 67]. Two placebo-controlled trials studied the use of combined biotin and chromium supplementation in type 2 diabetic subjects $[68,69]$. Improvements in glucose metabolism were noted in both trials. One trial demonstrated significant improvement in oral glucose tolerance and reduction in fructosamine after 4 weeks of followup [69]. The second trial demonstrated a reduction in glycosylated hemoglobin of $0.5 \%$ from a baseline of $8.7 \%$ in 447 subjects over 90 days [68].

With the promising results of these early studies, the potential benefits of biotin supplementation may be considered in diabetic and obese patients.

\section{Thiamine}

Thiamine is an essential micronutrient that acts as a cofactor for several key enzymes in glucose and aminoacid metabolism including transketolase, pyruvate dehydrogenase, $\alpha$-ketoglutarate dehydrogenase, and $\alpha$-keto acid decarboxylase [70]. The latter three are important regulatory enzymes that serve to mediate glycolysis, the citric acid and the pentose phosphate shunt pathways, respectively [70]. Thiamine deficiency leads to a relative reduction in these metabolic pathways and to increases in the polyol, hexosamine, protein kinase C, and advanced glycosylated end-product pathways of glucose metabolism that can lead to endothelial dysfunction and potentially worsen type 2 diabetes [71] (Table 1).

Thiamine is absorbed in the proximal small bowel mainly through active transport [72]. The recommended daily intake of thiamine is $1.2 \mathrm{mg}$, approximately $0.5 \mathrm{mg}$ per $1000 \mathrm{kcal}$ consumed [73]. Important food sources of thiamine include pork, red meat, wheat germ, eggs, fish, and legumes [73]. Thiamine is virtually absent in food products
TABle 1: Prevalence of micronutrient deficiencies in obesity and diabetes $[5,6,46,58-61]$.

\begin{tabular}{lcc}
\hline \multirow{2}{*}{ Micronutrient } & \multicolumn{2}{c}{ Prevalence of deficiency } \\
& Obesity & Type 2 diabetes \\
\hline Thiamine B1 & $15-29 \%$ & $17-79 \%^{\mathrm{a}}$ \\
Pyridoxine B6 & $0-11 \%$ & - \\
Cobalamin B12 & $3-8 \%$ & $22 \%$ \\
Folic Acid & $3-4 \%$ & - \\
Ascorbic acid C & $35-45 \%$ & $-{ }^{\mathrm{b}}$ \\
Vitamin A & $17 \%$ & - \\
Vitamin D & $80-90 \%{ }^{\mathrm{c}}$ & $85-90 \%{ }^{\mathrm{c}}$ \\
Vitamin E & $0 \%$ & $0 \%$ \\
Zinc & $14-30 \%$ & - \\
Chromium & - & $20-40 \%$ \\
Selenium & $58 \%$ & - \\
\hline
\end{tabular}

-Prevalence data not available

${ }^{a}$ Data includes type 1 diabetic patients

${ }^{b}$ Decreased levels of ascorbic acid have been reported in diabetes

'Prevalence reflects rates vitamin D insufficiency.

containing refined carbohydrates such as milled rice and simple sugars, yet the metabolism of these foods requires relatively high amounts of thiamine and may lead to depletion [74]. In subjects on thiamine deficient diets, total body thiamine stores can be depleted within 2-3 weeks [74].

Severe deficiency of thiamine can lead to wet or dry beriberi or Wernicke encephalopathy, depending on the tissues involved. Moderate deficiency of thiamine may affect glucose metabolism and impact diabetes and related complications [71].

Thiamine deficiency measured by direct plasma levels of thiamine or by elevated erythrocyte transketolase activity has been observed in 15-29\% of obese individuals planning to undergo weight loss surgery $[75,76]$. The prevalence of thiamine deficiency has been reported in 17-79\% of diabetic patients, although these studies include both type 1 and type 2 diabetic patients [77-79] (Table 1).

Evidence for the effect of thiamine supplementation to reduce the risk and severity of type 2 diabetes has been demonstrated in a number of studies. Cultured endothelial cells demonstrate reduced production of reactive oxidative species and improved function in high glucose concentrations in the presence of thiamine $[80,81]$. Both of these characteristics are expected to reduce the risk of diabetic complications and possibly reduce the risk of diabetes itself [8].

In a double-blind crossover trial, the administration of benfotiamine, a lipid soluble thiamine analogue, improved endothelial function, reduced markers of oxidative stress and reduced levels of advanced glycosylated end-products following a test meal in type 2 diabetic patients [82]. Amount of dietary thiamine intake has been correlated with levels of endothelial progenitor cells in type 2 diabetic patients [83].

Long-term studies investigating the use of thiamine supplementation in diabetic patients have not been performed. The potential exists for thiamine supplementation to modify the course of diabetes by modulation of glucose metabolic 
pathways. Given high rates of thiamine deficiency in obese individuals and diabetic patients, supplementation may be considered.

\section{Antioxidant Vitamins}

Despite importance of reactive oxygen species and increased oxidative stress in the development, progression, and associated complications of type 2 diabetes, trials using antioxidant treatment in both diabetic patients and patients with impaired fasting glucose have been largely disappointing and indicate little to no overall effect [84-86]. As a result, the routine supplementation with vitamin $\mathrm{E}$, vitamin $\mathrm{C}$, and vitamin $\mathrm{A}$ in diabetic patients is currently not recommended.

Vitamin E consists of a family of lipid soluble antioxidant compounds, of which $\alpha$-tocopherol is the most abundant in the diet [87]. In contrast to other micronutrients discussed in this paper, obese and diabetic individuals have low rates of vitamin E deficiency. Studies in these groups fail to find any individuals that are vitamin $\mathrm{E}$ deficient $[5,9]$.

The use of vitamin E was studied in the Heart Outcome Prevention Evaluation (HOPE) trial, in which 3654 diabetic patients were randomized to receive 400 i.u. of $\alpha$-tocopherol or placebo [88]. After 4.5 years of followup, no differences in cardiovascular outcomes, nephropathy, dialysis, or retinal laser therapy were seen between treatment groups. Several small trials show no differences in glycemic control with vitamin E supplementation in type 2 diabetics [89-92]. Although there are a few published trials that suggest modest improvements in glycosylated hemoglobin, $[93,94]$ a recent metaanalysis of 9 studies demonstrates no appreciable effect of vitamin E supplementation on glycemic control in type 2 diabetic patients [86].

Vitamin $\mathrm{C}$ or ascorbic acid is a water soluble antioxidant vitamin that does not have significant body stores. Limited intake of fruits and vegetables can lead to rapid depletion [5]. Plasma vitamin $\mathrm{C}$ levels correlate inversely with body mass index and deficiency of vitamin C is reported in 35-45\% of obese individuals planning to undergo bariatric surgery $[58,95]$. Diabetic patients have lower dietary intake and lower plasma levels of vitamin C than healthy controls [96].

In a population study of 232,007 older adults, vitamin C supplementation was associated with mildly lower rates of type 2 diabetes in a dose responsive manner. Individuals that took $500 \mathrm{mg}$ daily had a $9 \%$ reduction in prevalence of diabetes [97]. Data from the National Health and Nutrition Exam Study (NHANES) III cohort demonstrates significantly lower plasma levels of vitamin $\mathrm{C}$ in type 2 diabetics [98]. These results should be weighed carefully as population-based nutritional studies often have confounding factors.

Few clinical trials have examined the use of vitamin C supplementation in type 2 diabetic patients. One small randomized trial in 20 diabetic subjects demonstrated that $1000 \mathrm{mg}$ daily oral vitamin $\mathrm{C}$ supplementation improved glucose disposal rates after 4 months [99]. A second trial failed to show improvement in glucose metabolism or insulin resistance with $800 \mathrm{mg}$ daily vitamin C supplementation [100]. In this study, plasma levels of vitamin C rose significantly; however, adequate plasma vitamin C levels were not achieved.

Further studies in diabetic patients and in those at risk for developing diabetes may help to elucidate the role of vitamin $\mathrm{C}$ supplementation in this population. The high rate of vitamin $C$ deficiency in obese individuals suggests that supplementation may be beneficial. Increasing dietary intake of fruits and vegetables can also address this deficiency and is currently recommended as part of a lifestyle intervention for the prevention and treatment of type 2 diabetes [101].

\section{Conclusion}

As with nearly all biochemical processes, glucose metabolism and insulin signaling require cofactors and vitamins that are essential in the diet. Deficiencies in any of these micronutrients have potential to impair glucose metabolism and cause insulin resistance. Clinical evidence supporting this hypothesis regarding the metabolic effects of specific deficiencies including vitamin $\mathrm{D}$, chromium, biotin, thiamine and vitamin $\mathrm{C}$ is mounting. Unlike vitamin $\mathrm{E}$, which has little to no proven clinical effect when given as a supplement, these vitamins are known to be deficient at relatively high rates in obese individuals and in diabetic patients. Clinicians should consider addressing possible deficiencies of these micronutrients when advising obese patients who are at risk for the development of type 2 diabetes. The medical care plan for obesity should include lifestyle changes, healthy food choices with high-nutrient content foods as part of a balanced approach for the prevention of the development of type 2 diabetes. Use of specific vitamin supplements may adopted into this rational practice.

\section{Conflict of Interests}

The author has no potential conflicts of interest to disclose.

\section{References}

[1] R. T. Hurt, T. H. Frazier, S. A. McClave, and L. M. Kaplan, "Obesity epidemic: overview, pathophysiology, and the intensive care unit conundrum," Journal of Parenteral and Enteral Nutrition, vol. 35, no. 5, pp. 4S-13S, 2011.

[2] K. M. Flegal, M. D. Carroll, C. L. Ogden, and L. R. Curtin, "Prevalence and trends in obesity among US adults, 19992008," Journal of the American Medical Association, vol. 303, no. 3, pp. 235-241, 2010.

[3] B. A. Swinburn, G. Sacks, K. D. Hall et al., "The global obesity pandemic: shaped by global drivers and local environments," The Lancet, vol. 378, no. 9793, pp. 804-814, 2011.

[4] M. N. Riaz, M. Asif, and R. Ali, "Stability of vitamins during extrusion," Critical Reviews in Food Science and Nutrition, vol. 49, no. 4, pp. 361-368, 2009.

[5] O. Kaidar-Person, B. Person, S. Szomstein, and R. J. Rosenthal, "Nutritional deficiencies in morbidly obese patients: a new form of malnutrition? Part A: vitamins," Obesity Surgery, vol. 18, no. 7, pp. 870-876, 2008.

[6] O. Kaidar-Person, B. Person, S. Szomstein, and R. J. Rosenthal, "Nutritional deficiencies in morbidly obese patients: 
a new form of malnutrition? Part B: minerals," Obesity Surgery, vol. 18, no. 8, pp. 1028-1034, 2008.

[7] K. Niswender, "Diabetes and obesity: therapeutic targeting and risk reduction-a complex interplay," Diabetes, Obesity and Metabolism, vol. 12, no. 4, pp. 267-287, 2010.

[8] R. A. Defronzo, "From the triumvirate to the ominous octet: a new paradigm for the treatment of type 2 diabetes mellitus," Diabetes, vol. 58, no. 4, pp. 773-795, 2009.

[9] E. Strohmayer, M. A. Via, and R. Yanagisawa, "Metabolic management following bariatric surgery," Mount Sinai Journal of Medicine, vol. 77, no. 5, pp. 431-445, 2010.

[10] Institute of Medicine, Dietary Reference Intakes of Calcium and Vitamin D, National Academic Press, Washington, DC, USA, 2011.

[11] M. F. Holick, N. C. Binkley, H. A. Bischoff-Ferrari et al., "Evaluation, treatment, and prevention of vitamin D deficiency: an endocrine society clinical practice guideline," Journal of Clinical Endocrinology and Metabolism, vol. 96, no. 7, pp. 1911-1930, 2011.

[12] A. G. Pittas, J. Lau, F. B. Hu, and B. Dawson-Hughes, "Review: the role of vitamin $\mathrm{D}$ and calcium in type 2 diabetes: a systematic review and meta-analysis," Journal of Clinical Endocrinology and Metabolism, vol. 92, no. 6, pp. 2017-2029, 2007.

[13] R. Bland, D. Markovic, C. E. Hills et al., "Expression of 25 -hydroxyvitamin D3-1 $\alpha$-hydroxylase in pancreatic islets," Journal of Steroid Biochemistry and Molecular Biology, vol. 8990, pp. 121-125, 2004.

[14] J. A. Johnson, J. P. Grande, P. C. Roche, and R. Kumar, "Immunohistochemical localization of the 1,25(OH)2D3 receptor and calbindin D28k in human and rat pancreas," American Journal of Physiology, vol. 267, no. 3, pp. E356-E360, 1994.

[15] X. Palomer, J. M. González-Clemente, F. Blanco-Vaca, and D. Mauricio, "Role of vitamin D in the pathogenesis of type 2 diabetes mellitus," Diabetes, Obesity and Metabolism, vol. 10, no. 3, pp. 185-197, 2008.

[16] H. Wolden-Kirk, L. Overbergh, H. T. Christesen, K. Brusgaard, and C. Mathieu, "Vitamin D and diabetes: its importance for beta cell and immune function," Molecular and Cellular Endocrinology, vol. 347, no. 1-2, pp. 106-120, 2011.

[17] P. M. Bourlon, B. Billaudel, and A. Faure-Dussert, "Influence of vitamin D3 deficiency and 1,25 dihydroxyvitamin D3 on de novo insulin biosynthesis in the islets of the rat endocrine pancreas," Journal of Endocrinology, vol. 160, no. 1, pp. 87-95, 1999.

[18] A. W. Norman, B. J. Frankel, A. M. Heldt, and G. M. Grodsky, "Vitamin D deficiency inhibits pancreatic secretion of insulin," Science, vol. 209, no. 4458, pp. 823-825, 1980.

[19] Y. Tanaka, Y. Seino, M. Ishida et al., "Effect of vitamin D3 on the pancreatic secretion of insulin and somatostatin," Acta Endocrinologica, vol. 105, no. 4, pp. 528-533, 1984.

[20] K. E. Brock, W.-Y. Huang, D. R. Fraser et al., "Diabetes prevalence is associated with serum 25-hydroxyvitamin D and 1,25-dihydroxyvitamin D in US middle-aged Caucasian men and women: a cross-sectional analysis within the prostate, lung, colorectal and ovarian cancer screening trial," British Journal of Nutrition, vol. 106, no. 3, pp. 339-344, 2011.

[21] G. Grimnes, N. Emaus, R. M. Joakimsen et al., "Baseline serum 25-hydroxyvitamin D concentrations in the Tromsø Study 1994-95 and risk of developing type 2 diabetes mellitus during 11 years of follow-up," Diabetic Medicine, vol. 27, no. 10, pp. 1107-1115, 2010.
[22] G. Isaia, R. Giorgino, and S. Adami, "High prevalence of hypovitaminosis D in female type 2 diabetic population," Diabetes Care, vol. 24, no. 8, p. 1496, 2001.

[23] R. Scragg, I. Holdaway, V. Singh, P. Metcalf, J. Baker, and E. Dryson, "Serum 25-hydroxyvitamin D3 levels decreased in impaired glucose tolerance and diabetes mellitus," Diabetes Research and Clinical Practice, vol. 27, no. 3, pp. 181-188, 1995.

[24] R. Scragg, M. Sowers, and C. Bell, "Serum 25-hydroxyvitamin D, diabetes, and ethnicity in the Third National Health and Nutrition Examination Survey," Diabetes Care, vol. 27, no. 12, pp. 2813-2818, 2004.

[25] A. A. Tahrani, A. Ball, L. Shepherd, A. Rahim, A. F. Jones, and A. Bates, "The prevalence of vitamin D abnormalities in South Asians with type 2 diabetes mellitus in the UK," International Journal of Clinical Practice, vol. 64, no. 3, pp. 351$355,2010$.

[26] K. M. Behall, D. J. Schofield, J. G. Hallfrisch, J. L. Kelsay, and S. Reiser, "Seasonal variation in plasma glucose and hormone levels in adult men and women," The American Journal of Clinical Nutrition, vol. 40, no. 6, pp. 1352-1356, 1984.

[27] H. Ishii, H. Suzuki, T. Baba, K. Nakamura, and T. Watanabe, "Seasonal variation of glycemic control in type 2 diabetic patients," Diabetes Care, vol. 24, no. 8, p. 1503, 2001.

[28] J. Mitri, M. D. Muraru, and A. G. Pittas, "Vitamin D and type 2 diabetes: a systematic review," European Journal of Clinical Nutrition, vol. 65, pp. 1005-1015, 2011.

[29] J. Nagpal, J. N. Pande, and A. Bhartia, "A double-blind, randomized, placebo-controlled trial of the short-term effect of vitamin D3 supplementation on insulin sensitivity in apparently healthy, middle-aged, centrally obese men," Diabetic Medicine, vol. 26, no. 1, pp. 19-27, 2009.

[30] A. G. Pittas, S. S. Harris, P. C. Stark, and B. Dawson-Hughes, "The effects of calcium and vitamin D supplementation on blood glucose and markers of inflammation in nondiabetic adults," Diabetes Care, vol. 30, no. 4, pp. 980-986, 2007.

[31] P. R. von Hurst, W. Stonehouse, and J. Coad, "Vitamin D supplementation reduces insulin resistance in South Asian women living in New Zealand who are insulin resistant and vitamin D deficient-a randomised, placebo-controlled trial," British Journal of Nutrition, vol. 103, no. 4, pp. 549-555, 2010.

[32] I. H. de Boer, L. F. Tinker, S. Connelly et al., "Calcium plus vitamin D supplementation and the risk of incident diabetes in the women's health initiative," Diabetes Care, vol. 31, no. 4, pp. 701-707, 2008.

[33] D. Parekh, V. Sarathi, V. K. Shivane, T. R. Bandgar, P. S. Menon, and N. S. Shah, "Pilot study to evaluate the effect of short-term improvement in vitamin D status on glucose tolerance in patients with type 2 diabetes mellitus," Endocrine Practice, vol. 16, no. 4, pp. 600-608, 2010.

[34] J. Mitri, B. Dawson-Hughes, F. B. Hu, and A. G. Pittas, "Effects of vitamin D and calcium supplementation on pancreatic $\beta$ cell function, insulin sensitivity, and glycemia in adults at high risk of diabetes: the Calcium and Vitamin D for Diabetes Mellitus (CaDDM) randomized controlled trial," The American Journal of Clinical Nutrition, vol. 94, no. 2, pp. 486-494, 2011.

[35] B. Nikooyeh, T. R. Neyestani, M. Farvid et al., "Daily consumption of vitamin $\mathrm{D}$ - or vitamin $\mathrm{D}+$ calcium-fortified yogurt drink improved glycemic control in patients with type 2 diabetes: a randomized clinical trial," The American Journal of Clinical Nutrition, vol. 93, no. 4, pp. 764-771, 2011.

[36] R. Jorde and Y. Figenschau, "Supplementation with cholecalciferol does not improve glycaemic control in diabetic 
subjects with normal serum 25-hydroxyvitamin D levels," European Journal of Nutrition, vol. 48, no. 6, pp. 349-354, 2009.

[37] W. Mertz and K. Schwarz, "Relation of glucose tolerance factor to impaired intravenous glucose tolerance of rats on stock diets," American Journal of Physiology, vol. 196, no. 3, pp. 614-618, 1959.

[38] K. Schwarz and W. Mertz, "Chromium(III) and the glucose tolerance factor," Archives of Biochemistry and Biophysics, vol. 85, no. 1, pp. 292-295, 1959.

[39] C. M. Davis and J. B. Vincent, "Chromium oligopeptide activates insulin receptor tyrosine kinase activity," Biochemistry, vol. 36, no. 15, pp. 4382-4385, 1997.

[40] J. B. Vincent, "Elucidating a biological role for chromium at a molecular level," Accounts of Chemical Research, vol. 33, no. 7, pp. 503-510, 2000.

[41] R. O. Brown, S. Forloines-Lynn, R. E. Cross, and W. D. Heizer, "Chromium deficiency after long-term total parenteral nutrition," Digestive Diseases and Sciences, vol. 31, no. 6, pp. 661-664, 1986.

[42] H. Freund, S. Atamian, and J. E. Fischer, "Chromium deficiency during total parenteral nutrition," Journal of the American Medical Association, vol. 241, no. 5, pp. 496-498, 1979.

[43] K. N. Jeejeebhoy, R. C. Chu, E. B. Marliss, G. R. Greenberg, and A. Bruce-Robertson, "Chromium deficiency, glucose intolerance, and neuropathy reversed by chromium supplementation, in a patient receiving long term total parenteral nutrition," The American Journal of Clinical Nutrition, vol. 30, no. 4, pp. 531-538, 1977.

[44] M. Via, C. Scurlock, J. Raikhelkar, G. Di Luozzo, and J. I. Mechanick, "Chromium infusion reverses extreme insulin resistance in a cardiothoracic ICU patient," Nutrition in Clinical Practice, vol. 23, no. 3, pp. 325-328, 2008.

[45] S. A. McClave, R. G. Martindale, V. W. Vanek et al., "Guidelines for the provision and assessment of nutrition support therapy in the adult critically ill patient: society of critical care medicine (SCCM) and American society for parenteral and enteral nutrition (A.S.P.E.N.)," Journal of Parenteral and Enteral Nutrition, vol. 33, no. 3, pp. 277-316, 2009.

[46] C. Ekmekcioglu, C. Prohaska, K. Pomazal, I. Steffan, G. Schernthaner, and W. Marktl, "Concentrations of seven trace elements in different hematological matrices in patients with type 2 diabetes as compared to healthy controls," Biological Trace Element Research, vol. 79, no. 3, pp. 205-219, 2001.

[47] T. G. Kazi, H. I. Afridi, N. Kazi et al., "Copper, chromium, manganese, iron, nickel, and zinc levels in biological samples of diabetes mellitus patients," Biological Trace Element Research, vol. 122, no. 1, pp. 1-18, 2008.

[48] D. Ghosh, B. Bhattacharya, B. Mukherjee et al., "Role of chromium supplementation in Indians with type 2 diabetes mellitus," Journal of Nutritional Biochemistry, vol. 13, no. 11, pp. 690-697, 2002.

[49] S. Rajpathak, E. B. Rimm, T. Li et al., "Lower toenail chromium in men with diabetes and cardiovascular disease compared with healthy men," Diabetes Care, vol. 27, no. 9, pp. 2211-2216, 2004.

[50] E. M. Balk, A. Tatsioni, A. H. Lichtenstein, J. Lau, and A. G. Pittas, "Effect of chromium supplementation on glucose metabolism and lipids: a systematic review of randomized controlled trials," Diabetes Care, vol. 30, no. 8, pp. 2154-2163, 2007.

[51] W. T. Cefalu and F. B. Hu, "Role of chromium in human health and in diabetes," Diabetes Care, vol. 27, no. 11, pp. 2741-2751, 2004.
[52] C. L. Broadhurst and P. Domenico, "Clinical studies on chromium picolinate supplementation in diabetes mellitusa review," Diabetes Technology and Therapeutics, vol. 8, no. 6, pp. 677-687, 2006.

[53] U.S. Food and Drug Administration, Qualified Health Claims: Letter of Enforcement Discretion-Chromium Picolinate and Insulin Resistance (Docket No. 2004Q-0144), 2005.

[54] C. Fernandez-Mejia, "Pharmacological effects of biotin," The Journal of Nutritional Biochemistry, vol. 16, pp. 424-427, 2005.

[55] R. Rodriguez-Melendez and J. Zempleni, "Regulation of gene expression by biotin (review)," Journal of Nutritional Biochemistry, vol. 14, no. 12, pp. 680-690, 2003.

[56] J. C. Coggeshall, J. P. Heggers, M. C. Robson, and H. Baker, "Biotin status and plasma glucose levels in diabetics," Annals of the New York Academy of Sciences, vol. 447, pp. 389-392, 1985.

[57] M. Maebashi, Y. Makino, Y. Furukawa, K. Ohinata, S. Kimura, and S. Takao, "Therapeutic evaluation of the effect of biotin on hyperglycemia in patients with non-insulin diabetes mellitus," Journal of Clinical Biochemistry and Nutrition, vol. 14, pp. 211-218, 1993.

[58] M. Coupaye, K. Puchaux, C. Bogard et al., "Nutritional consequences of adjustable gastric banding and gastric bypass: a 1-year prospective study," Obesity Surgery, vol. 19, no. 1, pp. 56-65, 2009.

[59] M. C. Pflipsen, R. C. Oh, A. Saguil, D. A. Seehusen, and R. Topolski, "The prevalence of vitamin B12 deficiency in patients with type 2 diabetes: a cross-sectional study," Journal of the American Board of Family Medicine, vol. 22, no. 5, pp. 528-534, 2009.

[60] D. A. de Luis, D. Pacheco, O. Izaola, M. C. Terroba, L. Cuellar, and T. Martin, "Clinical results and nutritional consequences of biliopancreatic diversion: three years of follow-up," Annals of Nutrition and Metabolism, vol. 53, no. 3-4, pp. 234-239, 2008.

[61] S. Gehrer, B. Kern, T. Peters, C. Christofiel-Courtin, and R. Peterli, "Fewer nutrient deficiencies after laparoscopic sleeve gastrectomy (LSG) than after Laparoscopic Roux-Y-gastric bypass (LRYGB)-a prospective study," Obesity Surgery, vol. 20, no. 4, pp. 447-453, 2010.

[62] K. Dakshinamurti, V. V. Modi, and S. P. Mistry, "Some aspects of carbohydrates metabolism in biotin-deficient rats," Proceedings of the Society for Experimental Biology and Medicine, vol. 127, no. 2, pp. 396-400, 1968.

[63] K. Dakshinamurti and C. Cheah-Tan, "Biotin-mediated synthesis of hepatic glucokinase in the rat," Archives of Biochemistry and Biophysics, vol. 127, no. C, pp. 17-21, 1968.

[64] J. Chauhan and K. Dakshinamurti, "Transcriptional regulation of the glucokinase gene by biotin in starved rats," Journal of Biological Chemistry, vol. 266, no. 16, pp. 10035-10038, 1991.

[65] H. Sone, M. Ito, K. Sugiyama, M. Ohneda, M. Maebashi, and Y. Furukawa, "Biotin enhances glucose-stimulated insulin secretion in the isolated perfused pancreas of the rat," Journal of Nutritional Biochemistry, vol. 10, no. 4, pp. 237-243, 1999.

[66] E. Larrieta, M. L. L. de la Vega-Monroy, P. Vital et al., "Effects ofbiotin deficiency on pancreatic islet morphology, insulin sensitivity and glucose homeostasis," The Journal of Nutritional Biochemistry. In press.

[67] C. Zendejas-Ruiz I. Fernandez-Mejia, C. Revilla-Monsalve, S. Islas-Andrade, A Báez-Saldaña, and A. Cárdenas, "Biotin treatment increases insulin sensitivity in type 2 diabetics," Diabetes, vol. 52, supplement, 2003. 
[68] C. A. Albarracin, B. C. Fuqua, J. L. Evans, and I. D. Goldfine, "Chromium picolinate and biotin combination improves glucose metabolism in treated, uncontrolled overweight to obese patients with type 2 diabetes," Diabetes/Metabolism Research and Reviews, vol. 24, no. 1, pp. 41-51, 2008.

[69] G. M. Singer and J. Geohas, "The effect of chromium picolinate and biotin supplementation on glycemic control in poorly controlled patients with type 2 diabetes mellitus: a placebo-controlled, double-blinded, randomized trial," Diabetes Technology and Therapeutics, vol. 8, no. 6, pp. 636643, 2006.

[70] L. Bettendorff and P. Wins, "Thiamin diphosphate in biological chemistry: new aspects of thiamin metabolism, especially triphosphate derivatives acting other than as cofactors," FEBS Journal, vol. 276, no. 11, pp. 2917-2925, 2009.

[71] G. L.J. Page, D. Laight, and M. H. Cummings, "Thiamine deficiency in diabetes mellitus and the impact of thiamine replacement on glucose metabolism and vascular disease," International Journal of Clinical Practice, vol. 65, no. 6, pp. 684-690, 2011.

[72] G. Rindi and U. Laforenza, "Thiamine intestinal transport and related issues: recent aspects (44538)," Experimental Biology and Medicine, vol. 224, no. 4, pp. 246-255, 2000.

[73] US Department of Health and Human Services and US Department of Agriculture, Dietary Guidelines for Americans, US Government Printing Office, Washington, DC, USA, 7th edition, 2010.

[74] D. Lonsdale, "A review of the biochemistry, metabolism and clinical benefits of thiamin(e) and its derivatives," Evidencebased Complementary and Alternative Medicine, vol. 3, no. 1, pp. 49-59, 2006.

[75] L. Carrodeguas, O. Kaidar-Person, S. Szomstein, P. Antozzi, and R. Rosenthal, "Preoperative thiamine deficiency in obese population undergoing laparoscopic bariatric surgery," Surgery for Obesity and Related Diseases, vol. 1, no. 6, pp. 517522, 2005, discussion 22.

[76] L. Flancbaum, S. Belsley, V. Drake, T. Colarusso, and E. Tayler, "Preoperative nutritional status of patients undergoing roux-en-Y gastric bypass for morbid obesity," Journal of Gastrointestinal Surgery, vol. 10, no. 7, pp. 1033-1037, 2006.

[77] G. Jermendy, "Evaluating thiamine deficiency in patients with diabetes," Diabetes and Vascular Disease Research, vol. 3, no. 2, pp. 120-121, 2006.

[78] N. Saito, M. Kimura, A. Kuchiba, and Y. Itokawa, "Blood thiamine levels in outpatients with diabetes mellitus," Journal of Nutritional Science and Vitaminology, vol. 33, no. 6, pp. 421-430, 1987.

[79] P. J. Thornalley, R. Babaei-Jadidi, H. Al Ali et al., "High prevalence of low plasma thiamine concentration in diabetes linked to a marker of vascular disease," Diabetologia, vol. 50, no. 10, pp. 2164-2170, 2007.

[80] E. Ascher, P. V. Gade, A. Hingorani et al., "Thiamine reverses hyperglycemia-induced dysfunction in cultured endothelial cells," Surgery, vol. 130, no. 5, pp. 851-858, 2001.

[81] P. I. Lukienko, N. G. Mel'nichenko, I. V. Zverinskii, and S. V. Zabrodskaya, "Antioxidant properties of thiamine," Bulletin of Experimental Biology and Medicine, vol. 130, no. 9, pp. 874-876, 2000.

[82] A. Stirban, M. Negrean, B. Stratmann et al., "Benfotiamine prevents macro- and microvascular endothelial dysfunction and oxidative stress following a meal rich in advanced glycation end products in individuals with type 2 diabetes," Diabetes Care, vol. 29, no. 9, pp. 2064-2071, 2006.
[83] C. Y. Wong, J. Qiuwaxi, H. Chen et al., "Daily intake of thiamine correlates with the circulating level of endothelial progenitor cells and the endothelial function in patients with type II diabetes," Molecular Nutrition and Food Research, vol. 52, no. 12, pp. 1421-1427, 2008.

[84] R. Z. Fardoun, "The use of vitamin E in type 2 diabetes mellitus," Clinical and Experimental Hypertension, vol. 29, no. 3, pp. 135-148, 2007.

[85] B. Hasanain and A. D. Mooradian, "Antioxidant vitamins and their influence in diabetes mellitus," Current Diabetes Reports, vol. 2, no. 5, pp. 448-456, 2002.

[86] N. Suksomboon, N. Poolsup, and S. Sinprasert, "Effects of vitamin e supplementation on glycaemic control in type 2 diabetes: systematic review of randomized controlled trials," Journal of Clinical Pharmacy and Therapeutics, vol. 36, no. 1, pp. 53-63, 2011.

[87] M. W. Clarke, J. R. Burnett, and K. D. Croft, "Vitamin E in human health and disease," Critical Reviews in Clinical Laboratory Sciences, vol. 45, no. 5, pp. 417-450, 2008.

[88] S. Yusuf, G. Dagenais, J. Pogue, J. Bosch, and P. Sleight, "Vitamin E supplementation and cardiovascular events in high-risk patients: the heart outcomes prevention evaluation study investigators," The New England Journal of Medicine, vol. 342, no. 3, pp. 154-160, 2000.

[89] F. J. Gómez-Pérez, V. E. Valles-Sánchez, J. C. López-Alvarenga et al., "Vitamin E modifies neither fructosamine nor HbAlc levels in poorly controlled diabetes," Revista de Investigacion Clinica, vol. 48, no. 6, pp. 421-424, 1996.

[90] P. D. Reaven, D. A. Herold, J. Barnett, and S. Edelman, "Effects of vitamin E on susceptibility of low-density lipoprotein and low-density lipoprotein subfractions to oxidation and on protein glycation in NIDDM," Diabetes Care, vol. 18, no. 6, pp. 807-816, 1995.

[91] M. Boshtam, M. Rafiei, I. D. Golshadi, M. Ani, Z. Shirani, and M. Rostamshirazi, "Long term effects of oral vitamin $\mathrm{E}$ supplement in type II diabetic patients," International Journal for Vitamin and Nutrition Research, vol. 75, no. 5, pp. 341346, 2005.

[92] A. Gazis, D. J. White, S. R. Page, and J. R. Cockcroft, "Effect of oral vitamin $\mathrm{E}$ ( $\alpha$-tocopherol) supplementation on vascular endothelial function in type 2 diabetes mellitus," Diabetic Medicine, vol. 16, no. 4, pp. 304-311, 1999.

[93] D. Manzella, M. Barbieri, E. Ragno, and G. Paolisso, "Chronic administration of pharmacologic doses of vitamin E improves the cardiac autonomic nervous system in patients with type 2 diabetes," The American Journal of Clinical Nutrition, vol. 73, no. 6, pp. 1052-1057, 2001.

[94] G. Paolisso, A. D’Amore, D. Giugliano, A. Ceriello, M. Varricchio, and F. D’Onofrio, "Pharmacologic doses of vitamin $\mathrm{E}$ improve insulin action in healthy subjects and noninsulin-dependent diabetic patients," The American Journal of Clinical Nutrition, vol. 57, no. 5, pp. 650-656, 1993.

[95] K. P. Riess, J. P. Farnen, P. J. Lambert, M. A. Mathiason, and S. N. Kothari, "Ascorbic acid deficiency in bariatric surgical population," Surgery for Obesity and Related Diseases, vol. 5, no. 1, pp. 81-86, 2009.

[96] J. E. Shim, H. Y. Paik, C. S. Shin, K. S. Park, and H. K. Lee, "Vitamin C nutriture in newly diagnosed diabetes," Journal of Nutritional Science and Vitaminology, vol. 56, no. 4, pp. 217221, 2010.

[97] Y. Song, Q. Xu, Y. Park, A. Hollenbeck, A. Schatzkin, and H. Chen, "Multivitamins, individual vitamin and mineral supplements, and risk of diabetes among older U.S. adults," Diabetes Care, vol. 34, no. 1, pp. 108-114, 2011. 
[98] J. C. Will, E. S. Ford, and B. A. Bowman, "Serum vitamin C concentrations and diabetes: findings from the third National Health and Nutrition Examination Survey, 1988-1994," The American Journal of Clinical Nutrition, vol. 70, no. 1, pp. 49$52,1999$.

[99] G. Paolisso, V. Balbi, C. Volpe et al., "Metabolic benefits deriving from chronic vitamin $\mathrm{C}$ supplementation in aged non-insulin dependent diabetics," Journal of the American College of Nutrition, vol. 14, no. 4, pp. 387-392, 1995.

[100] H. Chen, R. J. Karne, G. Hall et al., "High-dose oral vitamin $C$ partially replenishes vitamin $C$ levels in patients with type 2 diabetes and low vitamin $C$ levels but does not improve endothelial dysfunction or insulin resistance," American Journal of Physiology, vol. 290, no. 1, pp. H137-H145, 2006.

[101] Y. Handelsman, J. I. Mechanick, L. Blonde et al., "American Association of Clinical Endocrinologists Medical Guidelines for clinical practice for developing a diabetes mellitus comprehensive care plan: executive summary," Endocrine Practice, vol. 17, no. 2, pp. 287-302, 2011. 


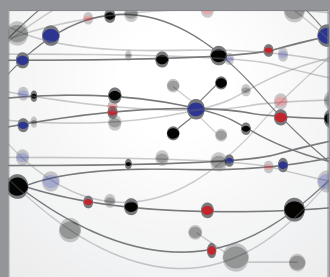

The Scientific World Journal
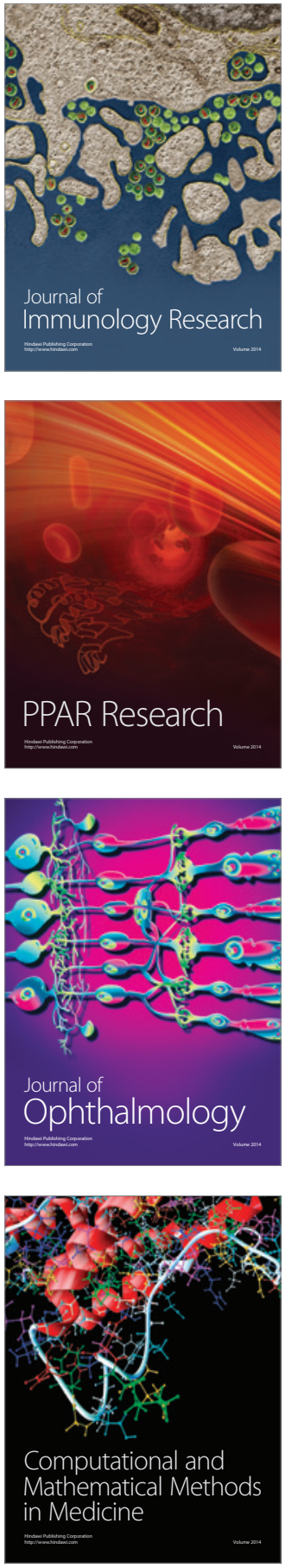

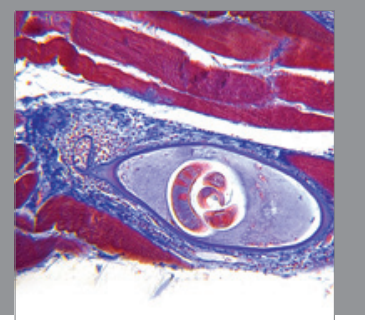

Gastroenterology

Research and Practice


\section{Hindawi}

Submit your manuscripts at

http://www.hindawi.com
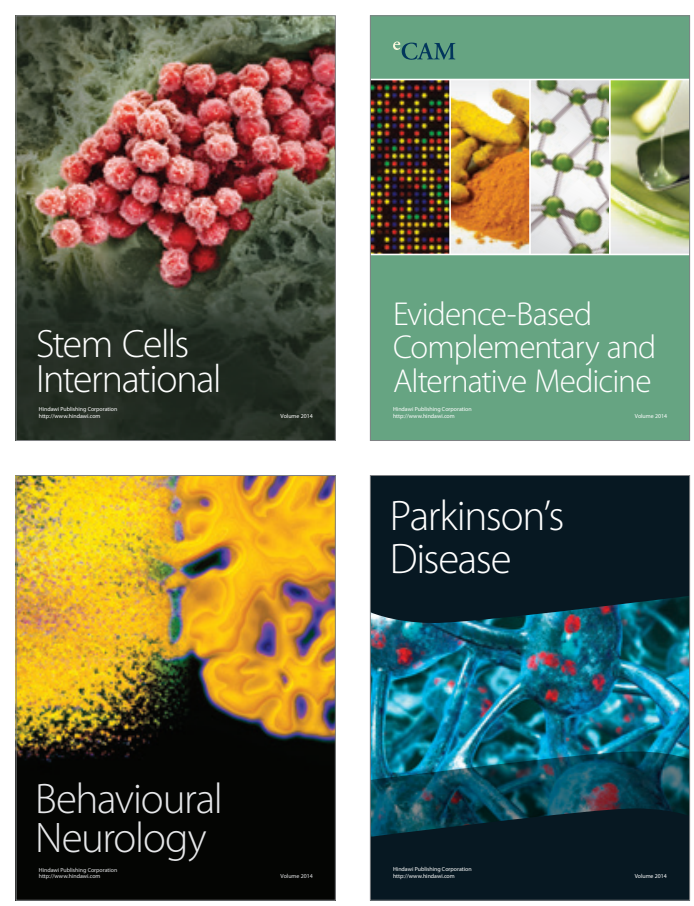

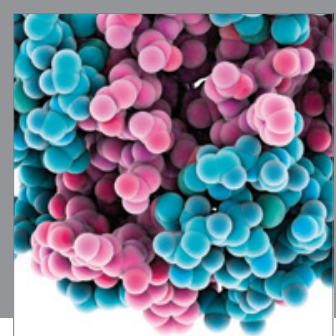

Journal of
Diabetes Research

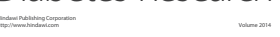

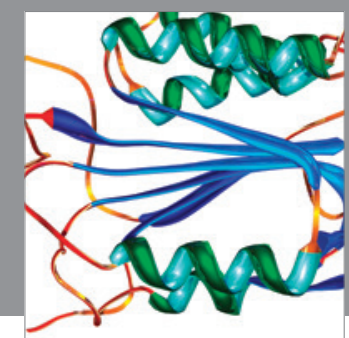

Disease Markers
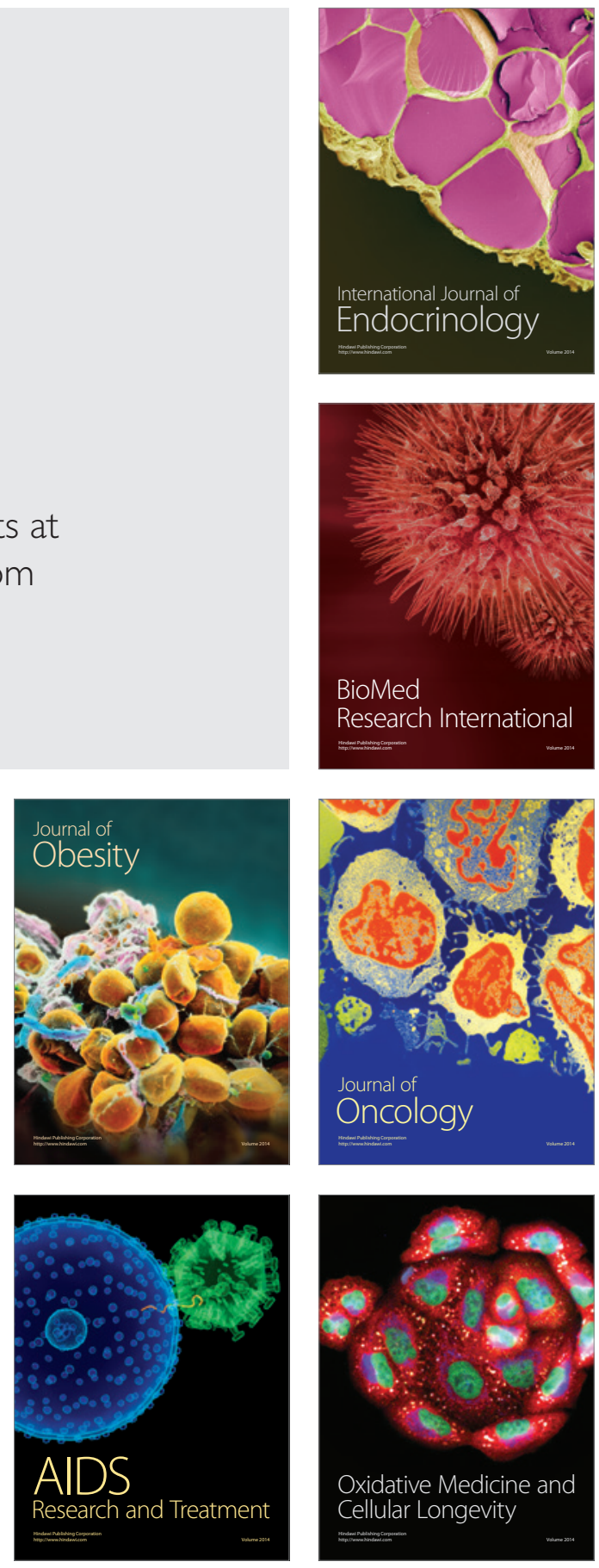